\title{
Alpha, Beta, gamma human PapillomaViruses (HPV) detection with a different sets of primers in oropharyngeal swabs, anal and cervical samples
}

Catia Sias $^{1 \dagger}$, Leonidas Salichos ${ }^{3 \dagger}$, Daniele Lapa ${ }^{1}$, Franca Del Nonno ${ }^{2}$, Andrea Baiocchini ${ }^{2}$, Maria Rosaria Capobianchi ${ }^{1}$ and Anna Rosa Garbuglia ${ }^{1 *}$

\begin{abstract}
Background: Recent studies have shown a 13-fold increase of oropharyngeal cancer in the presence of HPV, while a-HPV detection seems to be rare in oral cavity in comparison to anal or cervical district, many novel $\beta$ and $\gamma$ types have been isolated in this anatomical site suggesting a wide tropism range. Currently, there are no guidelines recommending HPV oral cavity screening as a mandatory test, and it remains unknown which HPV types should be included in HPV screening programs. Our goal was to assess HPV prevalence in oropharyngeal, anal, and cervical swabs using different sets of primers, which are able to amplify $a, \beta, \gamma$ HPV types.

Methods: We analysed the presence of HPV DNA in oropharyngeal $(n=124)$, anal $(n=186)$, cervical specimens $(n=43)$ from HIV positive and negative patients using FAP59/64 and MY09/11 primers. All untyped strains were genetically characterized through PCR amplification and direct sequencing of partial L1 region, and the resulting sequences were classified through phylogenetic analysis.

Results: HPV prevalence was $20.9 \%$ in 124 oropharyngeal swab samples, including infections with multiple HPV types (5.6\%). HPV prevalence in this anatomical site was significantly associated with serostatus: 63.3\%in HIV positive and $36.3 \%$ in HIV negative patients $(p<0.05)$.

Unclassified types were detected in 6 specimens. In our analysis, we did not observe any difference in HPV $(a, \beta, \gamma)$ prevalence between men and women. Overall, $\beta$ species were the most frequently detected $69.7 \%$. When using anal swabs, for HIV positive patients, $\beta$ genus prevalence was $1 \%$ and $\gamma$ genus was 3.7\% including 6 unclassified types. In cervical samples from 43 HIV positive women (18 HPV negative and 25 positive by MY09/11 PCR), only one sample was positivite for $\beta_{1}$ species (2.4\%) using FAP primers. Six of the untyped strains clustered with sequences from species 7, 9, 10, 8,12 of $\gamma$ genus. Four sequences remained unclassified. Finally, $\beta$ and $\gamma$ HPV prevalence was significantly lower than their respective HPV prevalence as identified by the Luminex system in all anatomical sites that were analyzed in previous studies.
\end{abstract}

Conclusion: This study provides new information about viral isolates present in oropharyngeal site and it will contribute to improve the monitoring of HPV infection.

Keywords: Human papillomaviruses, Betapapillomavirus, Gammapapillomavirus, HPV diagnosis, HPV detection methods, Oropharyngeal HPV infection

\footnotetext{
* Correspondence: argarbuglia@iol.it

${ }^{+}$Catia Sias and Leonidas Salichos authors have contributed equally to this work.

'Laboratory of Virology, "Lazzaro Spallanzani" National Institute for Infectious

Diseases, IRCCS, Via Portuense, 292, 00149 Rome, Italy

Full list of author information is available at the end of the article
}

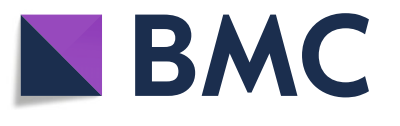

(c) The Author(s). 2019 Open Access This article is distributed under the terms of the Creative Commons Attribution 4.0 International License (http://creativecommons.org/licenses/by/4.0/), which permits unrestricted use, distribution, and reproduction in any medium, provided you give appropriate credit to the original author(s) and the source, provide a link to the Creative Commons license, and indicate if changes were made. The Creative Commons Public Domain Dedication waiver (http://creativecommons.org/publicdomain/zero/1.0/) applies to the data made available in this article, unless otherwise stated. 


\section{Introduction}

Human papillomavirus (HPV) persistent infections are considered the primary cause of ano-genital cancer, where greater than $99 \%$ of cervical cancer and more than $60 \%$ of anal cancer contain HPV DNA [1, 2]. Throughout the past years, several studies have suggested the link between HPV infection and other epithelial cancers, including cutaneous and oropharyngeal cancers. Oropharyngeal cancers are often referred to as "head and neck cancer" (HNC), and mainly include squamous-cell carcinoma which occurs in the oral cavity, base of tongue, tonsils, adenoids pharynx and larynx. Recent studies on HPV infection in oral exfoliated cells have shown that there is a 13-fold higher risk for oropharyngeal cancer in the presence of virus [3-5]. The highest prevalence (up to 50\%) for these HPV associated cancers has been found in the tonsillar cancers sub-set [6-8]. Since HPV16 presented a global prevalence in oropharyngeal squamous cell carcinoma (OPSCC) and oral squamous cell carcinoma (OSCC) of 40.6 and $14.9 \%$ respectively [9], IARC categorized this genotype as a risk factor with for the pathogenesis of both cancers [10]. Additionally, other HPV types have also been linked with these cancers, including HPV18, 31, and 33 [11] including $\beta$ and $\gamma$ types [4]. Furthermore, while $\alpha$-HPV detection seems to be rare in oral cavity in comparison to anal or cervical districts [12], many novel $\beta$ and $\gamma$ types have been isolated in oral cavity [13] suggesting a wide tropism range of these genera [14]. At the same time, different studies on HPV prevalence provided contradicting result for $\beta$ and $\gamma$ types not only in oropharyngeal site, but also in cervical and anal anatomical sites [14-19].

To date, there are no guidelines recommending HPV oral cavity screening as a mandatory test, and no HPV DNA test has been approved for HPV detection in oral cavity. In addition, it remains unknown which HPV types should be included in oral cavity screening. Agalliou [4] highlighted the link between $\beta, \gamma$ HPV types and oral cancers, assessing the presence of HPV types which are not generally detected with commercial assays in cervical cancer screening. Even though different methods have been used to detect novel HPV types, the association between new $\beta$ and $\gamma$ HPV types and oral cavity cancer has not yet been established.

In this study, we analyzed the presence of HPV DNA in oral, anal, and cervical specimens collected from HIV positive and HIV negative individuals, living in the same geographic area (regione Lazio) by using MY09/11 [20, 21] FAP59/64 primers [22]. These primers, both targeting highly conserved region within L1 ORF, are considered broad range PV primers and allow the detection of the great majority of already known and officially recognized HPV types. MY09/11 had been used in $\alpha$ HPV detection in cervical sites, where they showed good sensitivity in alpha HPV types amplification [21], while FAP primers officially recognized HPV from $\alpha-P V, \beta-P V$, and $\gamma$-PV genera, and might detect potentially new types [22-25]. This property is particularly relevant, since $y$ and $\beta$ papillomaviruses have been already identified in several anatomic sites $[14,26]$. Granted that that HPV prevalence is significantly higher among HIV infected people and at multiple anatomic sites [26-29] we included both HIV positive and HIV negative people in our study in order to also verify whether $\beta$ and $\gamma$ HPV positivity is influenced by host immune status.

\section{Materials and methods}

\section{Study population and sample collection}

This is a retrospective study carried out at Laboratory of Virology INMI L Spallanzani on residual oropharyngeal samples collected for respiratory virus detection, anal and cervical swabs collected for HPV testing in diagnostic routine. The Hospital ethics committee approved the protocol. Date of birth, date of swabs sampling, HIV serostatus were recorded from Institutional database. In HIV positive patients, the most recent CD4 T cell count ( \pm 1 month from the date of sample collection) and HIV RNA viral load ( \pm 1 month from the date of sample) with a detection limit of $40 \mathrm{cp} / \mathrm{ml}$ (Abbott Molecular Inc., Des Plaines, Il, USA) were used to correlate clinical features and HPV positivity.

Oropharyngeal swabs -Oropharyngeal samples were collected as following: the nylon-flocked tip was rotated 3-4-times against right and left buccal mucosa, palatine, tonsils, upper and lower pharynx area. The swab was then plunged and stirred in $1.5 \mathrm{~mL}$ DMEM medium with streptomycin and ampicillin. Specimens were refrigerated within 3-5 h after collection until processing.

Anal swabs -We retrospectively analysed 186 anal swabs previously tested by MY09/11 primers and typed by CLART HPV2 Clinical array or Sanger sequencing (see HPV detection and typing section, below). One hundred samples belonged to HIV positive women (50 HPV positive by MY09/11 PCR and 50 negative by MY09/11 PCR), 86 anal swabs were collected from men who have sex with men (MSM). All MSM specimen resulted positive in MY09/11 PCR.

Cervical swabs - A total of 43 cervical swabs (18 HPV negative and $25 \mathrm{HPV}$ positive, assigned by MY09/11 PCR) were considered in this study. All samples belonged to HIV positive women.

General characteristics of HIV infected patients are presented in Additional file 1: Table S1.

\section{DNA isolation}

Oropharyngeal swabs were removed from the medium which we divided in two parts: half part was used for detecting respiratory viruses panel (Influenza-A, B, RSV, 
rhinovirus, coronaviruses, metapneumovirus, adenovirus) and the other half was employed in testing HPV DNA, having been stored at $-80^{\circ} \mathrm{C}$ until use. Before nucleic acid extraction, all specimens were pre-treated. Briefly, $600 \mu \mathrm{L}$ of clinical material was digested with $20 \mu \mathrm{L}$ proteinase K solution (QIAGEN, Hilden Germany) and lysed with AL lysis buffer (QIAGEN, Hilden, Germany) at $56^{\circ} \mathrm{C}$ for $10 \mathrm{~min}$. Nucleic acid extraction was done with a magnetic bead-based automated platform (QIASYMPHONY, Hilden, Germany) in accordance with the manufacturer's instructions. Nucleic acids were eluted in $60 \mu \mathrm{L}$ of AVE elution buffer (QIAGEN, Hilden, Germany). Nucleic acid from anal and cervical swabs were extracted as described elsewhere [30, 31].

Samples that were $\beta$-globin negative were excluded from the study $[32,33]$.

\section{Human papillomavirus detection and genotyping}

Ten $\mu \mathrm{L}$ of eluted nucleic acids were employed for evaluating the presence of HPV types by using MY09(5'CGTCCMARRGGAWACTGATC3') and MY11(5'GCMCAGGGWCATAAYAATGG3') [20, 21] PCR and FastStart DNA polymerase (Roche Diagnostics GmbH, Mannheim, Germany). The PCR assay conditions were: $95^{\circ} \mathrm{C}$ for $5 \mathrm{~min}$, then 39 cycles (denaturation $95^{\circ} \mathrm{C} / 30 \mathrm{~s}$, annealing $55^{\circ} \mathrm{C} / 45 \mathrm{~s}$, and extension $72^{\circ} \mathrm{C} / 1$ min). One last step for extension was employed at $72^{\circ} \mathrm{C}$ for $10 \mathrm{~min}$. Fifteen $\mu \mathrm{L}$ of the PCR products were mixed with 6 loading solution in 1.8\% agarose gel electrophoresis stained by ethidium bromide and run for $30 \mathrm{~min}$ at $130 \mathrm{~V}$. HPV genotyping of positive samples was conducted using Genomica Clinical HPV array (Genomica, Madrid, Spain). CLART HPV2 clinical array HPV is able to detect: $6,11,16,18,26,31,33,35,39,40,42,43,44$, $45,51,52,53,54,56,58,59,61,62,66,68 \mathrm{a}$, and b, 70 , $71,72,73,81,82,83,84,85$, and 89 .

All adequate samples were retested using FAP 59 (5'TAACWGTIGGICAYCCWTATT3') and FAP 64 (5'CCWATATCWVHCATITCICCATC3') primers [22] able to detect $\alpha, \beta$ and $\gamma$ HPV types. FastStart DNA polymerase were used in this assay condition: $5 \mathrm{~min}$ at $94{ }^{\circ} \mathrm{C}$, 40 cycles (denaturation $94^{\circ} \mathrm{C} / 30 \mathrm{~s}$, annealing $52^{\circ}$ $\mathrm{C} / 45 \mathrm{~s}$, and extension $72{ }^{\circ} \mathrm{C} 1 \mathrm{~min}$ ) followed by a final extension step at $72{ }^{\circ} \mathrm{C}$ for $7 \mathrm{~min}$. PCR products were also run on agarose gel. Positive samples with FAP set of primers and those positive with MY09/11 PCR protocol, but negative in Genomica typing assay were purified and sequenced on the automated ABI Prism 3100 instrument, by using a BigDye Terminator cycle sequencing kit (Applied Biosystems, Warrington, UK).

\section{Phylogenetic analysis}

HPV sequences were aligned using mafft [34] using the L-INS-I method. After visual inspection using Seaview
[35] we removed sample sequence Q1359 and Q1017 were excluded from the alignment because they represented mixed infection and the Sanger sequence interpretation was not optimal. Reference sequences HM999999_HPV147 and GU129016_HPV148 were also excluded from the alignment. Then, we further implemented gblocks [36] to remove ambiguous positions using the least stringent options. To infer a maximum likelihood tree, we implemented RAxML [37] using a GTRCAT model, with 100 bootstrap replicates. Tree visualization was achieved using Figtree [38]. Finally, pairwise similarity matrices were constructed using BLAST.

\section{Results}

HPV detection in oropharyngeal swabs, anal and cervical samples

Oropharyngeal swabs-A total of 124 oropharyngeal swabs with $\beta$-globin positive signal were considered in this study. HPV prevalence was $20.9 \%$ (26/124), including infections with multiple HPV types (7/124, 5.6\%) (Table 1). MY09/11 PCR gave positive results in 18 samples. However, a BLAST search against GenBank indicated that 5 amplified fragments were identical to human sequences $(5 / 124,4 \%)$, thus true HPV positive rate was estimated at $10.5 \%$.

Out of 13, three samples were identified as $\alpha$ and ten as $\beta$ types. Alpha-types were detected in two HIV positive patients $(2 / 55,3.6 \%)$, and in 1 HIV negative patient. HPV $\alpha$-types, 16 and 70, were detected in HIV positive subjects $(2 / 55,3.6 \%)$ after being typed by CLART HPV2 clinical array, while HPV13 was amplified in HIV negative subject $(1 / 69,1.4 \%)$; it was typed by Sanger sequencing. All $\beta$ HPV types belonged to $\beta_{2}$ species (Table 1 ), and HPV145 was the most frequent type (4/10), both in HIV positive and HIV negative patients; 20 samples were identified as positive by FAP PCR. No specific amplicons were observed. Seven FAP-detected HPV types were found in samples that also gave positive results with MY09/MY11 PCR (Table 1). Types $\beta_{1}$ were the most represented $(n=13)$, while one sample was identified as $\gamma$ type (HPV132, $\left.\gamma_{12}\right)$. Additionally, one mixed infection (Q1017) and 5 untyped HPV strains were also detected. Among $\beta_{1}$ species, the most frequent types were HPV5 $(n=5,38.6 \%)$ and HPV19 $(\mathrm{n}=5,38.6 \%)$. Three multiple infections harboured $\beta_{1}$ and $\beta_{2}$ types, whereas $\beta_{2}$ types and untyped strains were observed in 4 other multiple infections. No multiple infection harboured $\alpha$ with $\beta$ or $\gamma$ species (Table 1). Overall, $\beta$ species were most prevalent $(n=23 / 33,69.7 \%)$. HPV distribution differed significantly when the number of HPV $\beta, \gamma$-types were considered in HIV positive and HIV negative subjects: $21(21 / 33,63.6 \%)$ vs $12(12 / 33,36.3 \%)$ respectively (Chi square test, $p<0.005)$. HIV positive people with HPV in 
Table 1 HPV types detected with 2 different primers set in oropharyngeal swabs from HIV positive and HIV negative patients

\begin{tabular}{|c|c|c|c|}
\hline & Sample code (sex) & MY09/11PCR & FAP59/64 PCR \\
\hline \multirow[t]{16}{*}{ HIV positive patients } & Q200 M & & $\mathrm{HPV} 19\left(\beta_{1}\right)$ \\
\hline & Q227 F & HPV145 $\left(\beta_{2}\right)$ & HPV19( $\left.\beta_{1}\right)$ \\
\hline & Q255 F & HPV110 $\left(\beta_{2}\right)$ & \\
\hline & Q266 F & HPV145 $\left(\beta_{2}\right)$ & $\operatorname{HPV} 5\left(\beta_{1}\right)$ \\
\hline & Q447 F & & $\operatorname{HPV} 5\left(\beta_{1}\right)$ \\
\hline & Q532 F & & HPV132( $\left.\gamma_{12}\right)$ \\
\hline & Q581 M & & $\operatorname{HPV} 5\left(\beta_{1}\right)$ \\
\hline & Q637 F & & $\operatorname{HPV} 5\left(\beta_{1}\right)$ \\
\hline & Q656 F & & $\S$ \\
\hline & Q686 M & & $\operatorname{HPV} 19\left(\beta_{1}\right)$ \\
\hline & Q947 F & $\operatorname{HPV} 70\left(a_{7}\right)$ & \\
\hline & Q996 F & HPV16(ag) & \\
\hline & Q1017 F & HPV120 $\left(\beta_{2}\right)$ & $\S$ \\
\hline & Q1234 F & $\operatorname{HPV} 17\left(\beta_{2}\right)$ & $\S$ \\
\hline & Q1644 F & & $\S$ \\
\hline & Q1766 M & $\mathrm{HPV} 17\left(\beta_{2}\right)$ & $\S$ \\
\hline \multirow[t]{10}{*}{ HIV negative patients } & Q127 M & HPV145 $\left(\beta_{2}\right)$ & $\S$ \\
\hline & Q425 F & & $\mathrm{HPV} 8\left(\beta_{1}\right)$ \\
\hline & Q718 F & & $\operatorname{HPV} 19\left(\beta_{1}\right)$ \\
\hline & Q739 M & HPV120 $\left(\beta_{2}\right)$ & \\
\hline & Q760 M & HPV145 $\left(\beta_{2}\right)$ & $\operatorname{HPV} 20\left(\beta_{1}\right)$ \\
\hline & Q1133 M & $\mathrm{HPV} 17\left(\beta_{2}\right)$ & \\
\hline & Q1643 M & & $\operatorname{HPV} 19\left(\beta_{1}\right)$ \\
\hline & Q1657 M & & $\operatorname{HPV} 20\left(\beta_{1}\right)$ \\
\hline & Q1833 M & & $\operatorname{HPV} 5\left(\beta_{1}\right)$ \\
\hline & Q2050 M & HPV13 $\left(a_{10}\right)$ & \\
\hline
\end{tabular}

$\S$ untyped HPV strains; $F$, female, $M$, male

oropharyngeal swabs showed a mean CD4 $\mathrm{T}$ cell count of $532.3 \pm 275.6$. Among HIV positive patients with detectable HPV, 6/16 had no detectable HIV RNA in plasma and the other patients $(n=10)$ showed a mean RNA copies/mL169.0 \pm 130.0 .

HPV prevalence rates were compared for statistical significance, using a Chi squared test, in men and women both HIV positive and HIV negative. However, no difference was observed (Chi square test, $p>0.05$ ).

Anal swabs- Eighty-six anal swabs from MSM resulted positive by MY09/11 PCR, and 100 anal swabs from women (50 HPV positive by MY09/11 PCR and 50 negative by MY09/11 PCR) were retested with FAP primers.

Among MSM anal swabs, 15 samples showed single HPV infection by CLART array testing, and 71 patients harboured multiple HPV infection with at least one high risk (HR) type. In $61.2 \%$ of samples we observed a clinically evident anal pathology, including 7 subjects with anal intraepithelial neoplasia (AIN) II, 46 patients with AIN I. Among HPV positive women, 18 harboured a single infection (AIN II, $n=0$; AIN I, $n=5$ ); atypical squamous cells of undetermined significance (ASC-US), $\mathrm{n}=0$; normal, $n=13$ ) and 31 samples showed HPV multiple infection, all with at least $1 \mathrm{HR}$ type (62\%) (AIN 2,n =0; AIN I, $n=9$; normal cytology, $n=22$ ). HPV type was undetermined in one sample. Among single infection with AIN I, one specimen was infected with a low risk (LR)Type (HPV81). Nineteen anal swab specimens were identified as HPV positive by FAP primers detection (female anal swabs, $n=3$; male anal swabs, $n=16$ ) (Table 2). Overall $\alpha$-type strains were detected in 9 samples with FAP primers which were not previously detected by MY09/11 primers. All but one $\alpha$-type strains were also detected with $\alpha$ mucosal HPV multiple infection typed with CLART HPV2 clinical array which included at least one HR type. HPV $\beta_{2}$ types (HPV9 and HPV37) were found in two specimens co-infected with $\alpha$ HPV types; 2 specimens harboured $\gamma_{10}$ HPV types (HPV121 and HPV180), both associated with type $\alpha$ HPV multiple infections. All FAP untyped strains $(n=6)$ were found in anal specimens infected by $\alpha$ types with at least one high HR type. Considering cytological aspects, 12/19 samples, which resulted positive with FAP primer PCR, had AIN (I, II) lesions, while 7/19 samples showed normal cytology (Table 2).

Among anal swabs from females $(n=100)$, only 3 samples (3.0\%), previously tested MY09/11 HPV positive, resulted HPV positive with FAP primer (HPV32, $\alpha_{1}$ species; HPV114, $\alpha_{3}$ species; HPV90, $\alpha_{14}$ species). No untyped HPV strains were observed among female samples.

Overall, $\beta$ genus prevalence was $1 \%$ and $\gamma$ genus was $3.7 \%$ including untyped isolates.

Mean of CD4 T cell count was $690.7 \pm 343.9$ cells $/ \mu \mathrm{L}$. Overall 170/186 patients (91.4\%) were under antiretroviral therapy (ART). All patients without ART had a CD4 $\mathrm{T}$ cell count $>400 / \mu \mathrm{L}$. Current ART use was not associated with risk of $\beta$ and $y$ infection (Chi square test, $p>0.05)$.

Cervical swabs-Twelve specimens showed a single HPV infection, and 13 had multiple infections by CLART HPV2 array; 17/25 samples harboured at least 1 HR genotype.

Cytology findings were available for 20 specimens already resulted positive by CLART HPV2 clinical array: 10 had normal cytology, 6 were ASC-US or low grade squamous intraepithelial lesion (LSIL), 3 harboured HPV single infections, 3 showed HPV multiple infections, and 4 were high grade squamous intraepithelial lesion (HSIL). All MY09/11 HPV negative women $(n=18)$ showed normal cytological findings. Eleven/43 cervical samples resulted FAP positive (25.6\%). However, only 6 
Table 2 Different HPV genera detected in male and female anal swabs by FAP primers

\begin{tabular}{|c|c|c|c|c|c|c|}
\hline Patient code & Sex & PCR by FAP primer & HPV genotypes typed by Genomica & Cytological lesion & CD4T cell count* & $\begin{array}{l}\text { HIVRNA } \\
\text { Viral load ^ }\end{array}$ \\
\hline & $a-1$ & & & & & \\
\hline Q74 & M & HPV 32 & $6 ; 16 ; 42 ; 45 ; 61 ; 52 ; 53 ; 59$ & AIN I & 482 & Detected $<40 \mathrm{cp} / \mathrm{ml}$ \\
\hline \multirow[t]{2}{*}{ Q497 } & $\mathrm{F}$ & HPV 32 & $6 ; 31 ; 42 ; 53$ & AIN I & 258 & 95 \\
\hline & $a-3$ & & & & & \\
\hline \multirow[t]{2}{*}{ Q802 } & $F$ & HPV114 & 16 & Negative & 986 & No detected \\
\hline & $a-6$ & & & & & \\
\hline Q1420 & M & HPV30 & $16 ; 70 ; 71 ; 83$ & AIN \| & 372 & Not detected \\
\hline Q1664 & M & HPV30 & $44 ; 51 ; 59 ; 81$ & Negative & 897 & 118 \\
\hline \multirow[t]{2}{*}{ Q1958 } & M & HPV30 & $33 ; 56 ; 58 ; 72$ & Negative & 226 & Detected $<40 \mathrm{cp} / \mathrm{ml}$ \\
\hline & $a-8$ & & & & & \\
\hline \multirow[t]{2}{*}{ Q1224 } & M & HPV43 & $11 ; 40 ; 68$ & AIN I & 421 & Not detected \\
\hline & $a-14$ & & & & & \\
\hline Q2167 & M & HPV90 & $33 ; 61 ; 72$ & AIN I & 797 & Detected $<40 \mathrm{cp} / \mathrm{ml}$ \\
\hline \multirow[t]{2}{*}{ Q1211 } & $\mathrm{F}$ & HPV90 & $35 ; 51 ; 84$ & AIN I & 372 & Detected $<40 \mathrm{cp} / \mathrm{ml}$ \\
\hline & $\beta-2$ & & & & & \\
\hline Q324 & M & HPV9 & $6 ; 53 ; 66$ & AIN I & 453 & Not detected \\
\hline \multirow[t]{2}{*}{ Q1420 } & M & HPV37 & $31 ; 70$ & Negative & 919 & Not detected \\
\hline & $\gamma-10$ & & & & & \\
\hline Q1652 & M & HPV121 & $6 ; 58$ & AIN I & 383 & 799 \\
\hline \multirow[t]{2}{*}{ Q1661 } & M & HPV180 & $31 ; 44 ; 56 ; 70$ & Negative & N.D. & N.D. \\
\hline & Uncla & & & & & \\
\hline Q654 & M & SE17 & $11 ; 31 ; 44 ; 51 ; 58 ; 62 ; 66$ & AIN I & 612 & 362 \\
\hline Q760 & M & FA79 & $35 ; 44 ; 66 ; 81$ & AIN I & 601 & 185 \\
\hline Q763 & M & FAIMVS9 & $33 ; 58 ; 70 ; 81$ & AIN I & 392 & Not detected \\
\hline Q1539 & M & FA138 & $53 ; 66 ; 84 ; 85$ & Negative & 886 & 111 \\
\hline Q2164 & M & FA39 & $16 ; 33$ & Negative & 648 & Not detected \\
\hline Q1354 & M & MM7 & $31 ; 45$ & AIN I & 630 & Not detected \\
\hline
\end{tabular}

HPV human papillomavirus; ${ }^{*}$ cell $/ \mu \mathrm{l} ; \wedge$ copies $/ \mathrm{ml}$; N.D. not done

HPV types were not previously detected by MY09/11 primers. Five samples harboured $\alpha$ types (HPV90, $n=3$ $\alpha_{14} ;$ HPV32, $\mathrm{n}=1, \alpha_{1} ;$ HPV68 $\alpha_{7}, \mathrm{n}=1$ ), and only one specimen gave positivity for $\beta_{1}$ (HPV14) (2.4\%). The mean CD4 $\mathrm{T}$ cell count was $539 \pm 230$ cells $/ \mu \mathrm{L}$. Ninety-six percent of women were receiving ART per WHO guideline of starting ART at CD4T cell count < $350 \mathrm{cell} / \mathrm{mm}^{3}$. The woman harboring $\beta$ HPV strain was under ART. She had a CD4 T cell count of 540 cells $/ \mu \mathrm{L}$ and HIV RNA viral load was not detected.

Overall cervical and anal $\beta$ and $\gamma$ type positivity was not related to immune status as measured by CD4 $\mathrm{T}$ cell count (see Table 2) and ART treatment. Furthermore, the immune-re constitution could potentially prevent the persistence of $\beta$ and $\gamma$ types in anal and cervical sites or alternatively, $\beta$ and $\gamma$ types might show to have a less tropism to these anatomical sites.

\section{Phylogenetic analysis}

For the phylogenetic analysis of our untyped HPV samples we used 10 partial cds sampled sequences from major capsid protein L1 FAP PCR products and 59 reference sequences. Our reference sequences represent 50 classified and 9 untyped HPV sequences (see Table 3). According to our phylogenetic analysis, 6 of our sampled sequences (Q1766, Q1644, Q760, Q337, Q656 and Q654) clustered with previously classified reference sequences from species 7, 10, 8, 12 and $9-\gamma$ genus. Sequences Q763, Q1234, Q2164 and Q127 remained unclassified while showing great similarity with unclassified genomic regions AF489714 (FAMS9), KP692119, and AF217684.1 respectively (see Fig. 1 and Table 3).

\section{Discussion}

In HNC, particularly oropharyngeal cancer, the true prevalence and involvement of HPV in the 
Table 3 Untyped HPV strains detected by FAP59/64 primers

\begin{tabular}{|c|c|c|c|c|c|}
\hline & & Patient code & Closest strain & GenBank accession number & Nucleotide sequence similarity(\%) \\
\hline \multirow[t]{10}{*}{ HIV positive } & \multirow[t]{5}{*}{ Anal swabs } & Q654 & Isolate SE17 & JF906538.1 & $97 \%$ \\
\hline & & Q760 & Isolate FA79 & AF455142.1 & $99 \%$ \\
\hline & & Q763 & Isolate FAIMVS9 & AF489714.1 & $99 \%$ \\
\hline & & Q1539 & Mixed $^{a}$ & & \\
\hline & & $\begin{array}{l}\text { Q2164 } \\
\text { Q1354 }\end{array}$ & $\begin{array}{l}\text { Isolate FA39 } \\
\text { MM7 }\end{array}$ & $\begin{array}{l}\text { AF217684.1 } \\
\text { KC869667 }\end{array}$ & $\begin{array}{l}97 \% \\
98 \%\end{array}$ \\
\hline & \multirow[t]{5}{*}{ Oral Swabs } & Q337 & Isolate SE80 & $J \times 316020.1$ & $91 \%$ \\
\hline & & Q656 & Isolate FA97 & AF542103.1 & $97 \%$ \\
\hline & & Q1017 & Mixed $^{a}$ & & \\
\hline & & Q1234 & Isolate SE435 & KР6922119.1 & $99 \%$ \\
\hline & & $\begin{array}{l}\text { Q1644 } \\
\text { Q1766 }\end{array}$ & $\begin{array}{l}\text { Isolate FA12.2 } \\
\text { Isolate FA12.2 }\end{array}$ & $\begin{array}{l}\text { AY502596.1 } \\
\text { AY502596.1 }\end{array}$ & $\begin{array}{l}99 \% \\
99 \%\end{array}$ \\
\hline HIV negative & & Q127 & Isolate FA130 & AY468427.1 & $99 \%$ \\
\hline
\end{tabular}

${ }^{a}$ Sanger sequence gave no clear results in this sample

carcinogenetic process is still unknown. In fact, many studies report low prevalence of HPV obtained with systems used for the determination of HPV in cervical cancer screening (specific for $\alpha$ types), while other authors found higher prevalence when they used a platform able to detect HPV types belonging to genera other than $\alpha$ genus [4] both in oral cavity and in oral cancer [4, 39]. Agalliu recently found a correlation between the infection of some $\beta, \gamma$ HPV types and OSCC [4]. Furthermore, a recent meta- analysis provided additional evidence of the involvement of $\beta$ HPV types in the development of SCC in immunocompetent individuals [40]. Additionally, several mechanistic studies have consistently showed that E6 and E7 from several $\beta$ HPV types are able to target cellular proteins, such as p53 and $\mathrm{pRb}$, and to deregulate fundamental events involved in cellular transformation [41]. Thus $\beta$ and $\gamma$ HPV types detection could be included in a HPV screening test for oral cancer prevention, while a correct and suitable detection of HPV infection is becoming a priority. Currently, there are few studies that compare the HPV prevalence obtained using the protocols, which are normally for cervical cancer screening with those obtained using methods that are able to detect HPV types belonging to genera other than $\alpha$ or new ones. In this study, in order to assess the impact of PCR system in HPV prevalence determination, we carried out the detection of HPV with MY09/11 primer set, used in several genotyping molecular assays (for example Linear Array HPV genotyping Test, Roche Molecular system, CA USA; CLART HPV2 clinical arrays, Genomica, Madrid, Spain,) and FAP primers able to detect $\alpha, \beta, \gamma$ HPV types in several specimens. In oropharyngeal swabs samples, MY09/ 11 primer set was able to detect $39.4 \%$ (13/33) of HPV positive samples, while FAP set of primers detected the presence of HPV in 20/33 samples (60.6\%). Beta HPV was the main genus detected with a prevalence of $69.7 \%$ in HPV positive samples. This prevalence was in agreement with Bottalico et al. that used FAP primer and MY09/11 for detecting HPV in oral swabs [14]. HPV5 was the most frequent $\beta_{1}$ type and HPV145 the main type among $\beta_{2}$ species as described by Bottalico [14]. HPV38, which was reported as the main $\beta_{2}$ type in Forslund study [42], was absent in our samples. HR, namely HPV16, was observed only in one specimen from an HIV positive subject, whereas HR HPV were frequently observed in Bottalico study group [14]. The low frequency of HR could be imputed to immune status of the patients. Our patients were under HAART therapy and most of them had a CD4 T cell count $>200 / \mu$ l. No severe compromise of the immune-system could have limited a persistence of $\mathrm{HR}$ in this anatomical site. Unfortunately, no information was given in the Bottalico paper on patient CD4 $\mathrm{T}$ cell count, and this fact did not allow a correct comparison of these results. According to previous data reported by Forslund et al. [42], no difference in HPV prevalence was observed among men and women suggesting that host specific factors could contribute to HPV persistence and neoplasia development. Gamma genus represented $21.8 \%$ of HPV positive samples. To note, 6/7 $\gamma$ strains were untyped. Phylogenetic analysis revealed that 2 samples (Q1766 and Q1644) belonged to $\gamma_{7}$ species, while Q656 to $\gamma 12$ species and Q337 to $\gamma_{9}$ species. Interestingly, the oral untyped genotypes fell in different genera and cluster with the anal untyped strains, suggesting a specific tropism of these gamma types for oral mucosa. Gamma 12 and 7 were the most representative $\gamma$ species described by Bottalico in oral rinse and Agalliu in $\mathrm{HNC}$, suggesting their potential involvement in OSCC development.

Unlike Forslund and Hampras [42, 43], we did not identified any $\beta_{3}, \beta_{4}, \beta_{5}$ HPV types. This may be due to 


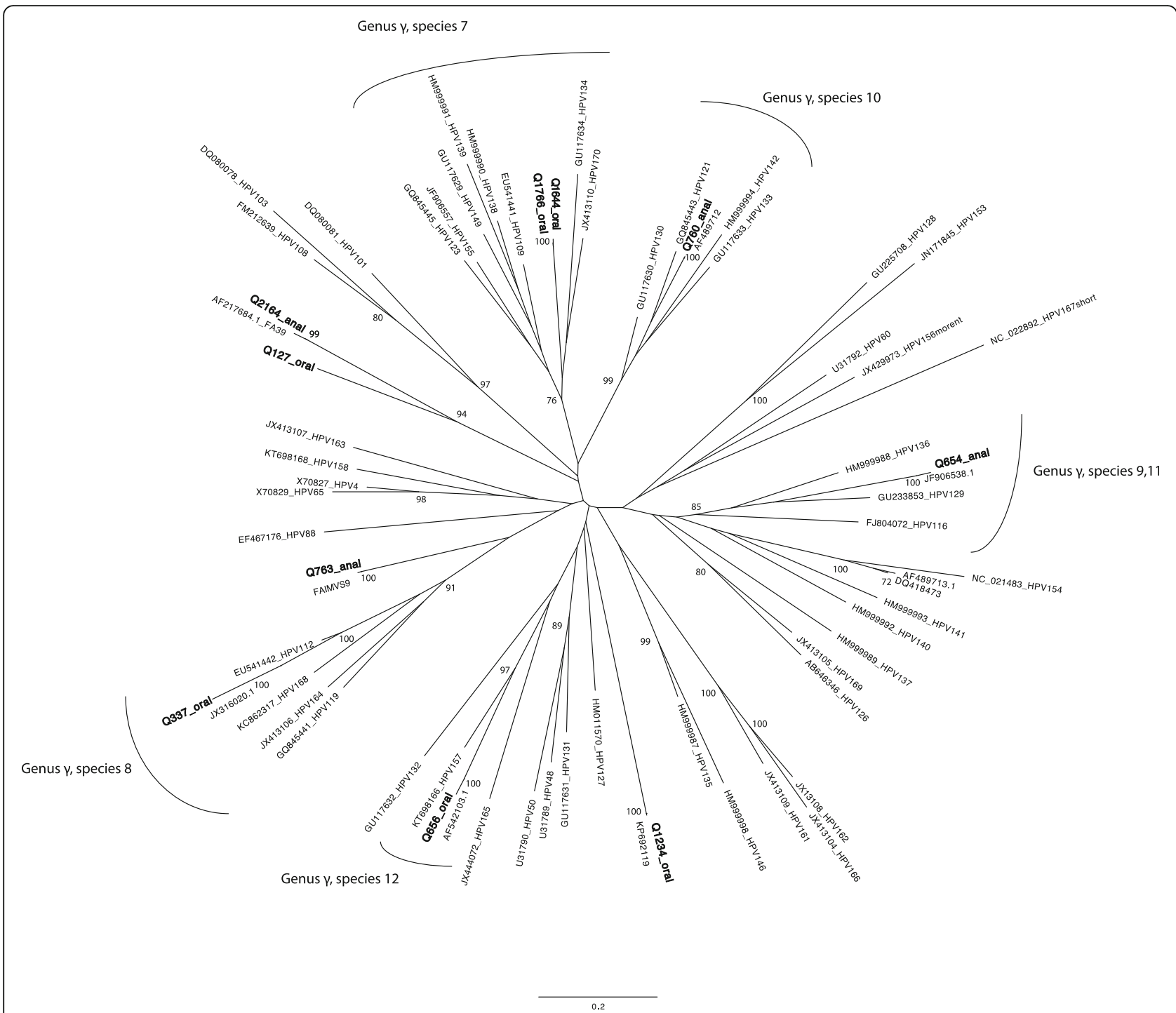

Fig. 1 A maximum likelihood phylogenetic analysis was inferred on 10 unknown collected samples (bold) and 59 reference sequences using the GTRCAT model. Out of 10 unknown samples, 6 sequences were clustered within previously classified HPV species lineages. Bootstrap supports lower than 70\% were excluded from the tree. GenBank accession number: MH647655- MH647663

the types of biological samples that were used or to differences in the efficiency of extraction methods that were applied, which could have influenced the outcome of PCR [44]. Finally, differences in results might also be explained by the geographical distribution of HPV types. In general, differences in HPV $\beta$ and $\gamma$ types and their prevalence were observed by the Luminex platform. According to HIM study [43], among $\beta_{1}$ genotypes, HPV12 and HPV5 were the prevalent genotypes. While, among $\beta_{2}$ strains, HPV38 was the most represented,and it was never detected in our samples. Interestingly HR HPV38 was also the main $\beta_{2}$ type observed also in Moscicki study, whereas HPV21 represented the main $\beta_{1}$ type [45]. A different pattern of $\beta$ types could be related to a different cellular input as described in a previous study
[46], where several $\beta$ HPV types showed essentially increasing prevalence with increasing DNA input. Beta HPV types 8, 14, 20, 21, 23, 38, and 92 showed increased prevalence only in higher DNA input groups [46]. This may impose compromises in comparisons between studies; for example, our HPV38 negative result could be explained by an insufficient DNA input in the PCR assay. Further research is needed to establish whether there is an influence between cell number input and HPV $\beta$ detection in oropharyngeal anatomical site and which cut-off would be suggested to avoid false negative results. Possible type-specific differences in sensitivity to cellular input have to be evaluated in wider studies. If they are confirmed, they may be explained by the different sensitivities in detection systems and/or in the 
different viral load spectra. We detected $9 \alpha$ strains in anal site FAP primers that had not been typed by Genomica, and $2 \beta_{2}$ types, HPV9 and HPV37, that had not been reported among oropharyngeal swabs. Beta types frequency was sensibly lower to that found by Luminex system reported by Torres et al. [17] which found $65.6 \%$ of $\beta$ types in anal swabs from HIV positive MSM and 59.1\% among HIV negative MSM. In this study, HPV12 and HPV 107 were the prevalent types among $\beta_{1}$ species, while HPV38 and HPV120 were the most frequently observed $\beta_{2}$ types. Among $\gamma$ genus, the $\gamma_{10}$ species was the most prevalent in both MSM HIV positive and -negative groups, while we observed only $\gamma$ untyped strains. Donà reported higher prevalence of $\beta$ (27.6\%) and $\gamma$ types (29.3\%) in a group of MSM similar to ours using the Luminex system [16]. Some hypothesis could put forth to explain these data: i) The Luminex system could be much more sensitive than the FAP system, or ii) that cross-reactivity could occur in $\beta$ and $\gamma$ types detection when $\alpha$ multiple infections are present. In literature, cross-reactivity was also observed among $\alpha$ genotypes. Preisler observed cross-reactivity both in LR and HR genotypes using HC2, COBAS, and APTIMA assays, despite what manufacturer claims: about $25 \%$ of HPVDNA results in primary screening accounting for cross-reactivity, regardless of the assay [47]. To obtain improved analytical and clinical performance, cross-reactivity studies should be focused, since this aspect could influence the effectiveness in a future head neck HPV cancer screening.

In cervical swabs the FAP primers mainly showed the presence of $\alpha$ genotypes (HPV90, $\alpha_{14} ;$ HPV32, $\alpha_{1}$ ) which were not detected by CLART HPV2 clinical array/ MY09-11primers and $1 \beta_{1}$ type (HPV14). This low prevalence of $\beta$ types confirms the data reported by Bottalico et al. [14], which found a prevalence of $1 \%$ of the $\beta$ types and 3\% of the $\gamma$ types in the cervical samples, emphasizing a weak $\beta$ and $\gamma$ type tropism towards the female genital mucosa. However, the genotypes HPV93 and HPV124, detected by Bottalico in cervical specimens, were never observed among our cervical samples, suggesting a different geographic distribution of HPV $\beta$ and $\gamma$ type similarly to that described for $\alpha$ genus. Conversely, these findings were in disagreement with those obtained by Luminex system, as described in previous study [18].

A quantitative detection of the viral load in hair follicles demonstrated that the $\beta$ genotype copy number was considerably lower than that reported for mucosal high-risk types from $\alpha$ genus in cervical tissue [48]. Thus, only comparable viral load detection studies with different methods and the potential for multiple infections detection could explain these differences in prevalence of $\beta$ types, which are reported in literature.
Overall, our results confirmed a prevalence of $>20 \%$ for HPV strains in the oropharyngeal anatomical district. The genus $\beta$ and $\gamma$ were predominant when the analysis was carried out with FAP primers. The discrepancy on the prevalence and HPV types reported in other studies $[16-18,49]$ seems to be due to the detection system: highest prevalence was always obtained with the Luminex system. Different sensitivity and specificity of HPV detection methods were also a problem in the determination of $\alpha \mathrm{HPV}$ types, as described in a systematic review where approximately $30-60 \%$ of all positive results showed discordance [50]. A global proficiency program like LabNet for $\alpha$ types in cervical HPV infection surveillance programs should be planned also for $\alpha, \beta$ and $\gamma$ HPV type detection in oropharyngeal samples [51]. Standardizing methods for oral sample collection and HPV detection would ensure comparability between different detection methods in oral cavity samples [52, 53].

In addition, considering that $\gamma$ genus has been growing rapidly (currently $98 \gamma$ types have been identified) surpassing $\alpha$ and $\beta$ genera, and that $77 \%$ of the new types deposited in the HPV center within 2015 belonged to $\gamma$ genus [54-56], our data reinforces the relevance of using primer sets able to detect a wide spectrum of HPV strains including $\beta$ and $\gamma$ types as well as new genotypes for HPV detection in the oropharyngeal anatomical site. This seems to be a crucial point since the meta genomic approach applied in some analysis [13] should be used with caution, taking in account the possibility of having an overestimation of HPV types [57] and requiring a confirmation of positivity by the Sanger method.

\section{Additional file}

Additional file 1 Table S1 Study population characteristics of HIV infected patients. (DOCX 14 kb)

\section{Acknowledgments \\ We are grateful to all member of Virology Laboratory INMI L. Spallanzani for sample collection. We thank Dr. Mariana Badescu for English editing. \\ Funding \\ The work was supported by grant "Ricerca corrente" from Italian Ministry of Health.}

Availability of data and materials

The nucleotide sequences of this study were submitted to GenBank.

Authors' contributions

ARG conceived and designed the research; CS, DL, FDN, AB performed the research; CS, DL, LS, MRC and ARG analyzed the data; ARG and LS wrote the manuscript. All authors read and approved the final manuscript.

Consent for publication

Not applicable.

Competing interests

The authors declare that they have no competing interests. 


\section{Publisher's Note}

Springer Nature remains neutral with regard to jurisdictional claims in published maps and institutional affiliations.

\section{Author details Diseases, IRCCS, Via Portuense, 292, 00149 Rome, Italy. ${ }^{2}$ Laboratory of Pathology, "Lazzaro Spallanzani" National Institute for Infectious Diseases, Yale University, New Haven, CT 06520, USA. \\ Received: 24 October 2018 Accepted: 15 February 2019 Published online: 04 March 2019}

'Laboratory of Virology, "Lazzaro Spallanzani" National Institute for Infectious IRCCS, Rome, Italy. ${ }^{3}$ Program in Computational Biology and Bioinformatics,

\section{References}

1. De Martel C, Plummer M, Vignat J, Franceschi S. Worldwide burden of cancer attributable to HPV by site, country and HPV type. Int J Cancer. 2017; 141(4):664-70

2. http://globocan.iarc.fr/

3. D'Souza G, Kreimer AR, Viscidi R, Pawlita M, Fakhry C, Koch WM, et al. Casecontrol study of human papillomavirus and oropharyngeal cancer. N Engl J Med. 2007;356(19):1944-56.

4. Agalliu I, Gapstur S, Chen Z, Wang T, Anderson RL, Teras L, et al. Associations of Oral $\alpha-, \beta$-, and $\gamma$-human papillomavirus types with risk of incident head and neck Cancer. JAMA Oncol. 2016 Jan 21. https://doi.org/ 10.1001/jamaoncol.2015.5504.

5. Capone RB, Pai SI, Koch WM, Gillison ML, Danish HN, Westra WH, et al. Detection and quantitation of human papillomavirus (HPV) DNA in the sera of patients with HPV-associated head and neck squamous cell carcinoma. Clin Cancer Res. 2000:6(11):4171-5.

6. Syrjänen S. HPV infections and tonsillar carcinoma. J Clin Pathol. 2004;57(5): 449-55.

7. Paz IB, Cook N, Odom-Maryon T, Xie Y, Wilczynski SP. Human papillomavirus (HPV) in head and neck cancer. An association of HPV 16 with squamous cell carcinoma of Waldeyer's tonsillar ring. Cancer. 1997:79(3):595-604.

8. Näsman A, Attner P, Hammarstedt L, Du J, Eriksson M, Giraud G, et al. Incidence of human papillomavirus (HPV) positive tonsillar carcinoma in Stockholm, Sweden: an epidemic of viral-induced carcinoma? Int J Cancer 2009:125(2):362-6. https://doi.org/10.1002/ijc.24339.

9. Ndiaye C, Mena M, Alemany L, Arbyn M, Castellsagué X, Laporte L, et al. HPV DNA, E6/E7 mRNA, and p16INK4a detection in head and neck cancers: a systematic review and meta-analysis. Lancet Oncol. 2014;15(12):1319-31. https://doi.org/10.1016/S1470-2045(14)70471-1.

10. Cogliano VJ, Baan R, Straif K, Grosse Y, Lauby-Secretan B, El Ghissassi F, et al. Preventable exposures associated with human cancers. J Natl Cancer Inst. 2011;103(24):1827-39. https://doi.org/10.1093/jnci/djr483 Epub 2011 Dec 12. Review.

11. Shin $\mathrm{KH}$, Park KH, Hong HJ, Kim JM, Oh JE, Choung PH, et al. Prevalence of microsatellite instability, inactivation of mismatch repair genes, p53 mutation, and human papillomavirus infection in Korean oral cancer patients. Int J Oncol. 2002;21(2):297-302.

12. Kreimer AR, Bhatia RK, Messeguer AL, González P, Herrero R, Giuliano AR. Oral human papillomavirus in healthy individuals: a systematic review of the literature. Sex Transm Dis. 2010:37(6):386-91.

13. Martin E, Dang J, Bzhalava D, Stern J, Edelstein ZR, Koutsky LA, et al. Characterization of three novel human papillomavirus types isolated from oral rinse samples of healthy individuals. J Clin Virol. 2014;59(1):30-7.

14. Bottalico D, Chen Z, Dunne A, Ostoloza J, McKinney S, Sun C, et al. The oral cavity contains abundant known and novel human papillomaviruses from the Betapapillomavirus and Gammapapillomavirus genera. J Infect Dis. 2011; 204(5):787-92

15. Mlakar B, Kocjan BJ, Hošnjak L, Fujs Komloš K, Milošević M, Poljak M. Betapapillomaviruses in the anal canal of HIV positive and HIV negative men who have sex with men. J Clin Virol. 2014;61(2):237-41. https://doi.org/ 10.1016/j.jcv.2014.07.009 Epub 2014 Jul 23.

16. Donà MG, Gheit T, Latini A, Benevolo M, Torres M, Smelov V, et al. Alpha, beta and gamma human papillomaviruses in the anal canal of HIV-infected and uninfected men who have sex with men. J Inf Secur. 2015;71(1):74-84.

17. Torres M, Gheit T, McKay-Chopin S, Rodríguez C, Romero JD, Filotico R, et al Prevalence of beta and gamma human papillomaviruses in the anal canal of men who have sex with men is influenced by HIV status. J Clin Virol. 2015;67:47-51

18. Sichero L, El-Zein M, Nunes EM, Ferreira S, Franco EL, Villa LL, et al. Cervical infection with cutaneous Beta and Mucosal alpha papillomaviruses. Cancer Epidemiol Biomark Prev. 2017;26(8):1312-20.

19. Wong MCS, Vlantis AC, Liang M, Wong PY, Ho WCS, Boon SS, Sze RKH, Leung C, Chan PKS, Chen Z. Prevalence and epidemiologic profile of Oral infection with alpha, Beta, and gamma papillomaviruses in an Asian Chinese population. J Infect Dis. 2018 Jul 2;218(3):388-97. https://doi.org/10.1093/ infdis/jiy 160.

20. Manos M, Ting MY, Wright DK, Lewis AJ, Broker TR, Wolinsky SM. The use of polymerase chain reaction amplification for the detection of genital human papillomaviruses. Cancer Cells. 1989;7:209-14.

21. Bernard HU, Chan SY, Manos MM, Ong CK, Villa LL, Delius H, Peyton CL, Bauer HM, Wheeler CM. Identification and assessment of known and novel human papillomaviruses by polymerase chain reaction amplification, restriction fragment length polymorphisms, nucleotide sequence, and phylogenetic algorithms. J Infect Dis. 1994;170(5):1077-85 Erratum in: J Infect Dis 1996 Feb;173(2):516. PMID:7963696.

22. Forslund $O$, Antonsson A, Nordin P, Stenquist B, Hansson BG. A broad range of human papillomavirus types detected with a general PCR method suitable for analysis of cutaneous tumours and normal skin. J Gen Virol. 1999;80(Pt 9):2437-43.

23. Kocjan BJ, Bzhalava D, Forslund O, Dillner J, Poljak M. Molecular methods for identification and characterization of novel papillomaviruses. Clin Microbiol Infect. 2015;21(9):808-16.

24. Ekström J, Mühr LS, Bzhalava D, Söderlund-Strand A, Hultin E, Nordin P, et al. Diversity of human papillomaviruses in skin lesions. Virology. 2013; 447(1-2):300-11.

25. Munday JS, Tucker RS, Kiupel M, Harvey CJ. Multiple oral carcinomas associated with a novel papillomavirus in a dog. J Vet Diagn Investig. 2015; 27(2):221-5.

26. Smelov $\mathrm{V}$, Muwonge R, Sokolova O, McKay-Chopin S, Eklund C, Komyakov B Gheit T. Beta and gamma human papillomaviruses in anal and genital sites among men: prevalence and determinants. Sci Rep. 2018;8(1):8241. https:// doi.org/10.1038/s41598-018-26589-w.

27. Palefsky JM, Holly EA, Ralston ML, Da Costa M, Greenblatt RM. Prevalence and risk factors for anal human papillomavirus infection in human immunodeficiency virus (HIV)-positive and high-risk HIV-negative women. J Infect Dis. 2001;183:383-91 Epub 2000 Dec 29.

28. Fakhry C, D'souza G, Sugar E, Weber K, Goshu E, Minkoff H, Wright R, Seaberg E, Gillison M. Relationship between prevalent oral and cervical human papillomavirus infections in human immunodeficiency virus-positive and -negative women. J Clin Microbiol. 2006:44(12):4479-85 Epub 2006 Oct 4.

29. Meiring TL, Mbulawa ZZA, Lesosky M, Coetzee D, Williamson AL. High diversity of alpha, beta and gamma human papillomaviruses in genital samples from HIV-negative and HIV-positive heterosexual south African men. Papillomavirus Res. 2017;3:160-7. https://doi.org/10.1016/j.pvr.2017.05. 001 Epub 2017 May 10.

30. Garbuglia AR, Gentile M, Del Nonno F, Lorenzini P, Lapa D, Lupi F, et al. An anal cancer screening program for MSM in Italy: prevalence of multiple HPV types and vaccine-targeted infections. J Clin Virol. 2015;72:49-54. https://doi. org/10.1016/j.jcv.2015.09.001 Epub 2015 Sep 11.

31. Garbuglia AR, Piselli P, Lapa D, Sias C, Del Nonno F, Baiocchini A, Cimaglia C, Agresta A, Capobianchi MR. Frequency and multiplicity of human papillomavirus infection in HIV-1 positive women in Italy. J Clin Virol. 2012; 54(2):141-6. https://doi.org/10.1016/j.jcv.2012.02.013 Epub 2012 Mar 20.

32. Vergori A, Garbuglia AR, Piselli P, Del Nonno F, Sias C, Lupi F, et al. Oral human papillomavirus DNA detection in HIV-positive men: prevalence, predictors, and co-occurrence at anal site. BMC Infect Dis. 2018;18(1):25.

33. Saiki RK, Scharf S, Faloona F, Mullis KB, Horn GT, Erlich HA, et al. Enzymatic amplification of beta-globin genomic sequences and restriction site analysis for diagnosis of sickle cell anemia. Science. 1985;230(4732):1350-4.

34. Katoh K, Misawa K, Kuma K, Miyata T. MAFFT: a novel method for rapid multiple sequence alignment based on fast Fourier transform. Nucleic Acids Res. 2002;30(14):3059-66.

35. Galtier N, Gouy M, Gautier C. SEAVIEW and PHYLO_WIN: two graphic tools for sequence alignment and molecular phylogeny. Comput Appl Biosci. 1996;12(6):543-8.

36. Castresana J. Selection of conserved blocks from multiple alignments for their use in phylogenetic analysis. Mol Biol Evol. 2000;17(4):540-52. 
37. Stamatakis A. RAxML-VI-HPC: maximum likelihood-based phylogenetic analyses with thousands of taxa and mixed models. Bioinformatics. 2006; 22(21):2688-90.

38. http://tree.bio.ed.ac.uk/software/figtree/

39. Sabol I, Smahelova J, Klozar J, Mravak-Stipetic M, Gheit T, Tommasino M, Grce M, Tachezy R. Beta-HPV types in patients with head and neck pathology and in healthy subjects. J Clin Virol. 2016;82:159-65. https://doi. org/10.1016/j.jcv.2016.07.019 Epub 2016 Jul 28.

40. Chahoud J, Semaan A, Chen Y, Cao M, Rieber AG, Rady P, Tyring SK. Association Between $\beta$-Genus Human Papillomavirus and Cutaneous Squamous Cell Carcinoma in Immunocompetent Individuals-A Metaanalysis. JAMA Dermatol. 2016;152(12):1354-1364. https://doi.org/10.1001/ jamadermatol.2015.4530.

41. Tommasino M. The biology of beta human papillomaviruses. Virus Res. 2017;231:128-38. https://doi.org/10.1016/j.virusres.2016.11.013 Epub 2016 Nov 14. Review.

42. Forslund $\mathrm{O}$, Johansson $\mathrm{H}$, Madsen $\mathrm{KG}$, Kofoed $\mathrm{K}$. The nasal mucosa contains a large spectrum of human papillomavirus types from the Betapapillomavirus and Gammapapillomavirus genera. J Infect Dis. 2013; 208(8):1335-41.

43. Hampras SS, Rollison DE, Giuliano AR, McKay-Chopin S, Minoni L, Sereday K, et al. Prevalence and concordance of cutaneous Beta human papillomavirus infection at mucosal and cutaneous sites. J Infect Dis. 2017;216(1):92-6.

44. D'Souza G, Sugar E, Ruby W, Gravitt P, Gillison M. Analysis of the effect of DNA purificationon detection of human papillomavirus in oral rinse samples by PCR. J Clin Microbiol. 2005:43(11):5526-35.

45. Moscicki AB, Ma Y, Gheit T, McKay-Chopin S, Farhat S, Widdice LE, et al. Prevalence and transmission of Beta and Gamma human papillomavirus in heterosexual couples. Open Forum Infect Dis. 4(1):2017, ofw216. https://doi. org/10.1093/ofid/ofw216. eCollection 2017 Winter.

46. Weissenborn SJ, Neale R, de Koning MN, Waterboer T, Abeni D, Bouwes Bavinck JN, et al. Prevalence and multiplicity of cutaneous beta papilloma viruses in plucked hairs depend on cellular DNA input. J Virol Methods. 2009;161(2):280-3.

47. Preisler S, Rebolj M, Ejegod DM, Lynge E, Rygaard C, Bonde J. Crossreactivity profiles of hybrid capture $\|$, cobas, and APTIMA human papillomavirus assays: split-sample study. BMC Cancer. 2016;16:510. https:// doi.org/10.1186/s12885-016-2518-4.

48. Weissenborn S, Neale RE, Waterboer T, Abeni D, Bavinck JN, Green AC, et al. Beta-papillomavirus DNA loads in hair follicles of immunocompetent people and organ transplant recipients. Med Microbiol Immunol. 2012;201(2):117-25.

49. Nunes EM, López RVM, Sudenga SL, Gheit T, Tommasino M, Baggio ML, et al. Concordance of Beta-papillomavirus across anogenital and oral anatomic sites of men: the HIM study. Virology. 2017;510:55-9.

50. De Thurah L, Bonde J, Lam JUH, Rebolj M. Concordant testing results between various human papillomavirus assays in primary cervical cancer screening: systematic review. Clin Microbiol Infect. 2018;24(1):29-36.

51. Eklund C, Forslund O, Wallin KL, Dillner J. Continuing global improvement in human papillomavirus DNA genotyping services: the 2013 and 2014 HPV LabNet international proficiency studies. J Clin Virol. 2018;101:74-85.

52. De Souza MMA, Hartel G, Whiteman DC, Antonsson A. Detection of oral HPV infection - comparison of two different specimen collection methods and two HPV detection methods. Diagn Microbiol Infect Dis. 2018;90(4): 267-71.

53. Wood ZC, Bain CJ, Smith DD, Whiteman DC, Antonsson A. Oral human papillomavirus infection incidence and clearance: a systematic review of the literature. J Gen Virol. 2017:98(4):519-26.

54. www.hpvcenter.se (Accessed 5 Sept 2018)

55. Bzhalava D, Eklund C, Dillner J. International standardization and classification of human papillomavirus types. Virology. 2015;476:341-4.

56. Mühr LSA, Eklund C, Dillner J. Towards quality and order in human papillomavirus research. Virology. 2018;519:74-6.

57. Hao Y, Yang L, Galvao Neto A, Amin MR, Kelly D, Brown SM, et al. HPViewer: sensitive and specific genotyping of human papillomavirus in metagenomic DNA. Bioinformatics. 2018;34(12):1986-95.

Ready to submit your research? Choose BMC and benefit from:

- fast, convenient online submission

- thorough peer review by experienced researchers in your field

- rapid publication on acceptance

- support for research data, including large and complex data types

- gold Open Access which fosters wider collaboration and increased citations

- maximum visibility for your research: over $100 \mathrm{M}$ website views per year

At BMC, research is always in progress.

Learn more biomedcentral.com/submissions 